\section{(6)}

OPEN ACCESS
'Department of Radiology, HealthCare Global Enterprises, Bangalore, Karnataka, India ${ }^{2}$ Department of Radiology, St Johns Medical College Hospital, Bangalore, Karnataka, India

\section{Correspondence to} Dr Sankar Neelakantan, dr.sankar@live.com

Accepted 6 September 2016

\title{
Hepatic hydatid disease presenting as secondary Budd-Chiari syndrome
}

\author{
Sankar Neelakantan, ${ }^{1}$ Arul Arokia Sensan Babu, ${ }^{2}$ Rakesh Anandarajan, ${ }^{2}$ Babu Philip ${ }^{2}$
}

\section{DESCRIPTION}

A 51-year-old man presented with a history of vague abdominal pain and progressively increasing abdominal distension. Abdominal examination revealed hepatomegaly with a firm nodular liver palpable below the costal margin with mild tenderness in the right hypochondriac region. General examination revealed no pedal oedema, ascites or jaundice. No significant history or drug history was elicited.

Imaging work up included a transabdominal ultrasound scan performed elsewhere which showed a multilocular cystic lesion in the right lobe of the liver with coarsened hepatic echotexture and surface nodularity. Serology was positive for hydatid disease.

Contrast-enhanced CT scan (CECT) of the abdomen performed at our centre revealed a large multilocular cystic lesion in the right lobe of the liver with enhancing walls and daughter cysts within (figure 1), with extrahepatic extension into the gastrohepatic ligament and transdiaphragmatic extension into the middle mediastinum through the bare area of the liver (figure 2). The lesion was noted to cause extrinsic compression of the retrohepatic inferior vena cava (IVC) so that the right and middle hepatic veins were not visible (figures 3 and 4). Volume redistribution, surface nodularity and altered parenchymal enhancement of the liver were also noted (figure 5). There was also omental fat stranding with mild ascites (figures 4 and 5). Based on the clinical presentation and imaging findings, a diagnosis of hepatic hydatid cyst causing secondary Budd-Chiari syndrome was made. The patient was advised surgery, but refused further

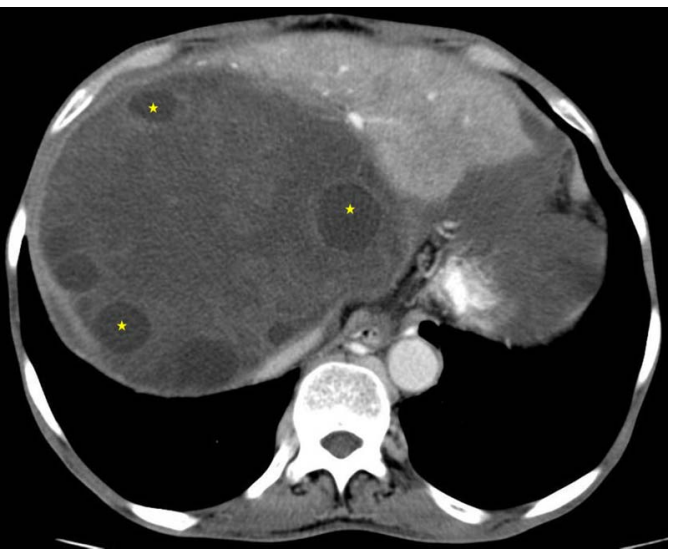

Figure 1 Axial contrast-enhanced section of the liver showing a large multilocular cystic lesion in the right lobe of the liver with enhancing walls and daughter cysts (star) within. treatment due to financial constraints. The patient was started on long-term albendazole and anticoagulation, and was advised follow-up after 3 months. On 3-month follow-up, he had significant relief of symptoms.

Hydatid disease, endemic to the tropics is caused by multiple species of the parasite Echinococcus, most commonly by E. granulosus. ${ }^{1}$ Budd-Chiari

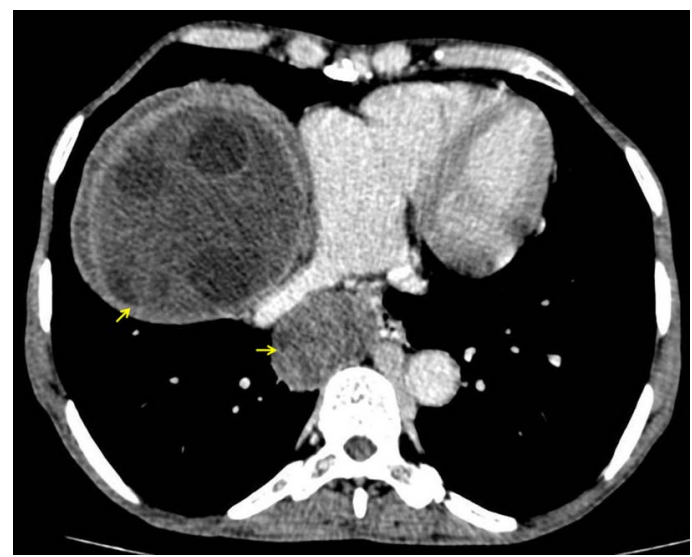

Figure 2 Axial contrast-enhanced CT section showing a transdiaphragmatic mediastinal extension of the lesion (arrows) through the bare area of the liver.

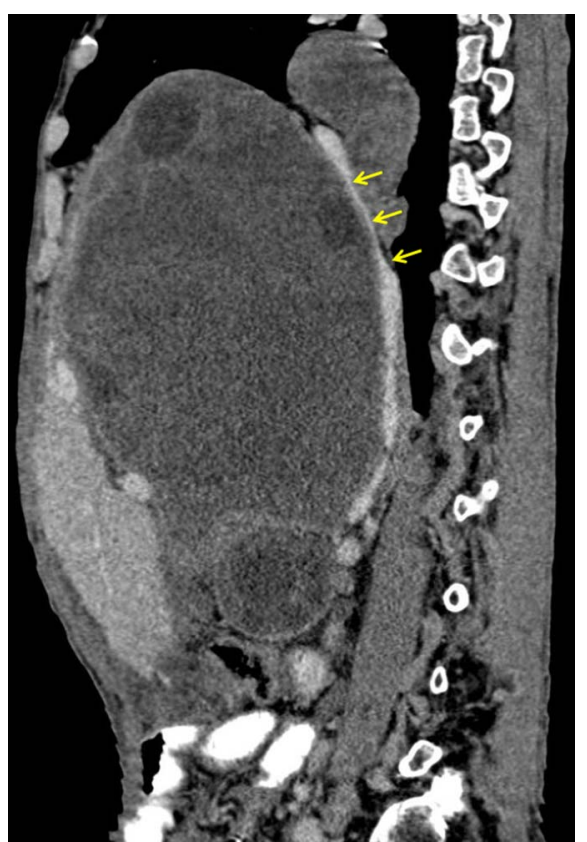

Figure 3 Sagittal contrast-enhanced CT section of the abdomen showing extrinsic compression of the retrohepatic (arrows) by the hepatic lesion. 


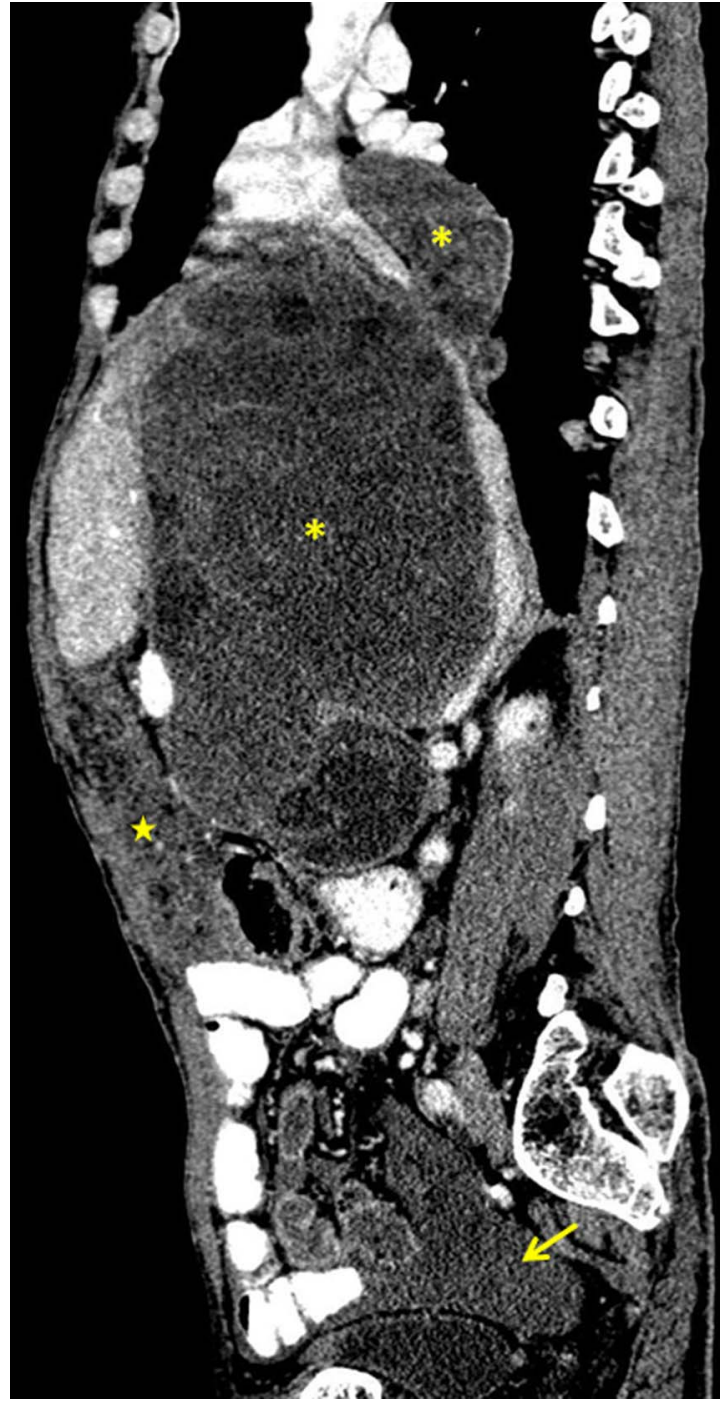

Figure 4 Sagittal contrast-enhanced section of the abdomen showing the lesion with mediastinal component $\left({ }^{*}\right)$, omental fat stranding (star) and ascites (arrow).

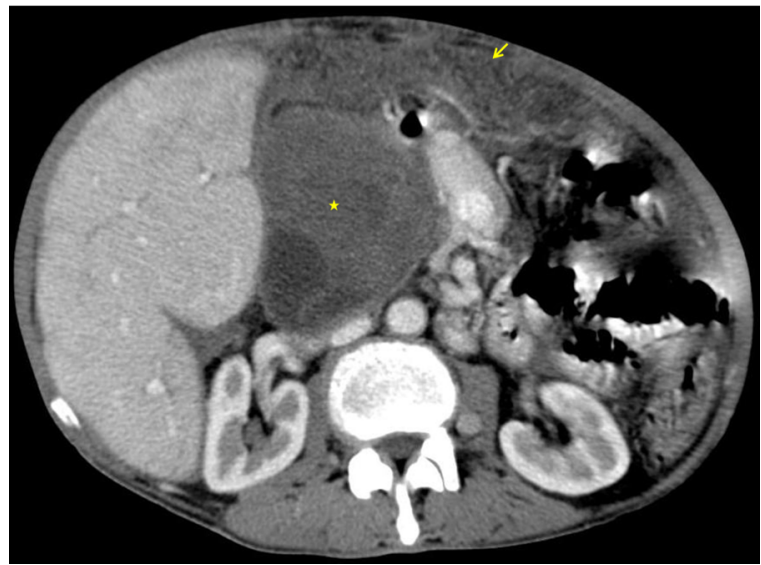

Figure 5 Axial contrast-enhanced CT section showing volume redistribution, surface nodularity and altered parenchymal enhancement of the liver.

\section{Learning points}

- Hepatic hydatid disease can rarely present with symptoms of chronic parenchymal liver disease secondary to Budd-Chiari syndrome.

- Budd-Chiari syndrome in hydatid disease is caused by extrinsic compression of the hepatic veins and/or inferior vena cava by the cyst, and also due to venous thrombosis secondary to inflammatory response elicited against the cyst contents.

- Ultrasonography with Colour Doppler can be used as an initial screening tool in these patients; however, cross-sectional imaging modalities such as contrast-enhanced CT abdomen and MRI help in better delineation of anatomy and surgical planning.

syndrome is described as extrinsic or intrinsic hepatic venous outflow obstruction at the level of hepatic venules, large hepatic veins, IVC or right atrium. ${ }^{2}$

The clinical presentation of hydatid disease can vary from incidental findings to severe complications such as cyst rupture, infection, portal hypertension, biliary communication, hollow viscera perforation or haematogenous spread to other organs such as the lungs, kidney and brain. ${ }^{3}$

However, hydatid cyst causing extrinsic compression of the IVC and presenting as Budd-Chiari syndrome is rare, as obstruction of at least two main suprahepatic veins should be present and the cysts should be considerably large and in appropriate position to cause significant compression. Apart from mechanical compression, inflammatory response to the cyst contents leading to phlebitis and subsequent thrombosis also contributes to the development of Budd-Chiari syndrome in hydatid disease. $^{4}$

Ultrasonography (USG) can be used as an initial screening tool in these patients to assess the size and position of the cyst, its relationship to the hepatic veins and IVC and to look for features of Budd-Chiari syndrome such as caudate lobe enlargement, ascites, splenomegaly and non-visualisation, narrowing or thrombosis of hepatic veins and IVC. Colour Doppler imaging shows monophasic or absent flow within the hepatic veins, IVC or both and intrahepatic collaterals. ${ }^{12}$ Cross-sectional imaging modalities such as CECT abdomen and MRI aid in better evaluation of the hepatic parenchyma, hepatic veins and IVC along with better delineation of the relationship of the cyst with these vascular structures, thereby aiding in surgical planning.

Surgery is generally required for cases of secondary Budd-Chiari syndrome due to hydatid cyst. However, venoplasty with stenting has also been performed in these patients, with good results. Medical management is usually only supplementary. ${ }^{5}$

Twitter Follow Sankar Neelakantan at @drsankar23

Contributors SN contributed to the idea/conceptualisation and contributed to the writeup. SN contributed to the writeup. AASB was involved in. editing. RA was responsible for final approval.

Competing interests None declared.

Patient consent Obtained.

Provenance and peer review Not commissioned; externally peer reviewed. 
Open Access This is an Open Access article distributed in accordance with the Creative Commons Attribution Non Commercial (CC BY-NC 4.0) license, which permits others to distribute, remix, adapt, build upon this work non-commercially, and license their derivative works on different terms, provided the original work is properly cited and the use is non-commercial. See: http://creativecommons.org/ licenses/by-nc/4.0/

\section{REFERENCES}

1 Akbulut S, Yilmaz M, Kahraman A, et al. Budd-Chiari syndrome due to giant hydatid cyst: a case report and brief literature review. J Infect Dev Ctries. 2013;7:489-93.
2 Menon KV, Shah V, Kamath PS. The Budd-Chiari syndrome. N Engl J Med 2004;350:578-85.

3 Pedrosa I, Saíz A, Arrazola J, et al. Hydatid disease: radiologic and pathologic features and complications. Radiographics 2000;20:795-817.

4 Bedioui H, Nouira K, Ayadi S, et al. Budd-Chiari syndrome secondary to hepatic echinococcosis. Gastroentérologie Clin Biol 2007: 31(8-9 Pt 1):721-4.

5 Sarawagi R, Keshava SN, Surendrababu NRS, et al. Budd-Chiari syndrome complicating hydatid cyst of the liver managed by venoplasty and stenting. Cardiovasc Intervent Radiol 2011;34(Suppl 2):202-5.

Copyright 2016 BMJ Publishing Group. All rights reserved. For permission to reuse any of this content visit http://group.bmj.com/group/rights-licensing/permissions.

BMJ Case Report Fellows may re-use this article for personal use and teaching without any further permission.

Become a Fellow of BMJ Case Reports today and you can:

- Submit as many cases as you like

- Enjoy fast sympathetic peer review and rapid publication of accepted articles

- Access all the published articles

- Re-use any of the published material for personal use and teaching without further permission

For information on Institutional Fellowships contact consortiasales@bmjgroup.com

Visit casereports.bmj.com for more articles like this and to become a Fellow 